\title{
Personality Traits among Psychiatric Out-patients with Suicide Attempt Attending Tertiary Care Hospital in Eastern Nepal
}

\section{Supriya Sherchan (Bhattachan)}

BP Koirala Institute of Health Sciences

Dhana Ratna Shakya ( $\sim$ drdhanashakya@yahoo.com )

B. P. Koirala Institute of Health Sciences https://orcid.org/0000-0002-3796-5426

\section{Nidesh Sapkota}

BP Koirala Institute of Health Sciences

\section{Rinku Gautam Joshi}

BP Koirala Institute of Health Sciences

\section{Madhur Basnet}

BP Koirala Institute of Health Sciences

\section{Binod Kumar Deo}

BP Koirala Institute of Health Sciences

\section{Research article}

Keywords: BPKIHS, mental illness, personality trait, Psychiatry out-patients, suicide attempt

Posted Date: June 17th, 2020

DOI: https://doi.org/10.21203/rs.3.rs-32987/v1

License: () (1) This work is licensed under a Creative Commons Attribution 4.0 International License. Read Full License 


\section{Abstract}

\section{Background-}

Suicide attempt is a self-injurious behaviour with a nonfatal outcome. Studies report increasing hospital admissions due to self-inflicted harm $(\mathrm{SIH})$ as well as a higher likelihood of associated psychosocial factors in SIH cases. We conducted a study to explore personality traits, socio-demographic profiles and psychiatric disorders among the suicide attempt cases in a tertiary care hospital setting of eastern Nepal.

\section{Methods-}

It was a descriptive study conducted with purposive sampling in a tertiary care hospital among suicide attempt cases who visited to out-patient department of psychiatry. A total of 113 cases (calculated sample size) were enrolled after written informed consent within study period of 1 year. Personality traits were analyzed by using 'Personality Trait Inventory' questionnaire. Psychiatric diagnosis was made as per the ICD-10 diagnostic criteria. Demographic variables were recorded in a semi-structured proforma.

Results-

Majority of the subjects were female, married and literate, with the most common age group being 20-29 and $<20$ years. Most of them were Hindu, from low socioeconomic status, joint family and cities, and were homemakers. Poisoning was the most common mode of suicide attempt and organo-phosphorous compounds the most common poison used. Some (13.3\%) had past and $5.3 \%$ had family history of suicidal attempt. Most cases 63 (55.8\%) were referred from Departments of Internal Medicine, followed by Emergency 28 (24.8\%), self 18 (15.9\%) and Paediatrics 4 (3.5\%). The common ICD-10 psychiatric diagnoses were: Substance use disorder, main being alcohol (42\%), Adjustment (34\%) and mood disorders (22\%). Emotional instability trait was the most common Personality Trait 70 (61.9\%), followed by Depressive tendency 46 (40.7\%). Personality disorder was present in 34\%; most common being Emotionally unstable personality disorder.

Conclusions-

Emotional instability trait was found in the highest number of suicide attempt patients.

\section{Background}

'Suicide' is derived from the Latin word for 'self-murder'. It is a fatal act that represents the person's wish to die. ${ }^{1}$ Suicide ideation and attempts are strongly predictive of suicide deaths; can result in negative consequences such as injury, hospitalization and loss of liberty. ${ }^{2}$ Psychiatric patients who attempt suicide have greater suicidal ideation, compared with the patients who do not attempt suicide. ${ }^{3}$

Clinical and community researches suggest links between suicide attempts and psychological traits of aggression, anger and impulsivity. Aggressiveness has been related to suicidality in mood disorders. ${ }^{4}$ 
Higher rates of lifetime aggression were observed in suicide attempters, compared to non-suicidal patients and lifetime aggression traits did correlate with suicide attempts in patients with mood disorder. ${ }^{4}$ Evidence on the relationship between personality traits and suicide is strongly emerging. Studies on the records of psychiatric patients with and without suicide attempt show that those who committed suicide possessed anger, aggression, anxiety and depression personality profiles. ${ }^{5}$ Depressed patients with borderline personality traits were characteristically vulnerable and had familial generalized anxiety disorder in comparison with other groups. ${ }^{6}$ Borderline and narcissistic personality pathology are linked as unique contributors to suicide related outcomes. ${ }^{7}$

Impulsivity and aggression have been demonstrated as important suicide risk factor, and are also typically present in patients with conduct disorder, personality disorders, substance use disorders and bipolar disorders. ${ }^{8}$ It is logical to hypothesize that impulsivity and suicidal behavior are correlated, because impulsive individuals might be more likely to enact a suicidal ideation. ${ }^{9}$ The personality trait of neuroticism, which is demonstrably associated with both depression and unstable mood, is also a focus of suicide research. Bowen et al. demonstrated that neuroticism could predict depression and suicidal thoughts. ${ }^{10}$ Some personality traits could also be predictive of psychiatric disorders. For example, neuroticism has been described as linking anxiety and depressive disorders. However, the underlying mechanisms that explain why some personality traits confer greater risk for suicidality and/or psychiatric disorders are not fully understood. Previous studies reported that personality disorders associated with affective lability and impulsivity had a higher prevalence among those who attempted suicide than other types of personality disorders. ${ }^{11,12}$ Thus, it is necessary to study and identify different aspects of personality traits, such as impulsivity or neuroticism, in people with or without psychiatric disorders who have attempted suicide.

\section{Methods}

The objective of current study was to explore personality traits, socio-demographic profiles and psychiatric disorders among the suicide attempt cases. It is a hospital based descriptive study conducted among psychiatry out-patients with history of suicide attempt, attending a tertiary care teaching hospital in eastern Nepal. We enrolled a total of 113 subjects which was sample size calculated based on the study titled 'Clinical Correlates Associated with Suicide Attempters at a Tertiary Care Centre of Eastern Nepal' by Pandey AK et al (2015) ${ }^{13}$ where prevalence of personality disorder (the correlate with the least prevalence among the correlates studied) was $24 \%$. Here, Prevalence $(p)=24 \%$ Compliment of prevalence $(q)=100-24=76 \%$

Using $Z=1.96$ at $95 \% \mathrm{Cl}$, Permissible Error $(\mathrm{PE})$ at $20 \%, \mathrm{~L}=20 \%$ of $24 \%=4.8 \%$

Sample size $(n)=Z^{2} X p q / L 2$

\section{$=(1.96)^{2} \times 24 \times 76 /(4.8) 2$}

Page $3 / 14$ 


\section{$=304$}

For finite population $n$,

$\mathrm{n}=\mathrm{n} 0 / 1+\mathrm{n} 0 / \mathrm{N}$

$\mathrm{n}=304 / 1+304 / 179$ (Based on previous year medical OPD record)

$=304 / 2.698$

\section{$=112.67(\cong 113)$}

Thus, total sample size $=113$ taken over the period of one year.

\section{Procedure}

The study was done after obtaining the approval of Research Committee of BPKIHS. Potentially eligible patients with suicide attempt, consulting in the Psychiatry OPD of BPKIHS was enrolled in the study. A written informed consent was taken before enrollment of the subject. Demographic profiles (age, sex, ethnicity, occupation, education and geographical areas, etc.) were documented in a semi-structured proforma. Psychiatric comorbidity was recorded as per detailed psychiatric assessment based on the ICD-10. All enrolled subjects were assessed with the application of the Personality Trait Inventory.

\section{Materials/ Instruments:}

1. 1. Semi-structured proforma was used to record all information related to socio-demographic profiles and clinical information including suicidality.

2. 2. Personality Trait Inventory for assessment of personality traits.

3. 3. International Classification of Diseases and Infirmity (ICD-10) for psychiatric diagnosis.

We used personality trait inventory consisting of 90 items to look for different traits in suicide attempt cases. Measurement of each trait was based on the questions of 10 items assigned for those particular 9 traits. As per the questions based on the inventory: Activity trait refers to an individual's tendency as outgoing, ambitious, rigidly organized, highly status-conscious, impatient, anxious, proactive, and concerned with time management. They are often high-achieving 'workaholics'. Superego are those who generally has high internal controls or standards. Introversion is withdrawn and reclusive; an introverted person is often cautious and secretive in dealing with others. Dominance trait reflects a person's tendency to be sociable, outgoing, active and assertive.

\section{Data Processing}

The coded proforma was collected and information were entered into computer. Quantitative and qualitative data processing were used with computer processing. The output of the project was able to 
provide data on the percentage, mean and standard deviation and summarized using frequency distribution tables and graphical methods (Bar diagram, Pie chart).

\section{Results}

Out of total of 113 cases enrolled, 71 (62.8\%) were female and $42(37.2 \%)$ male. Mean age was 28.27 years, with mean standard deviation of 12.317. Age groups (20-29) and $(<20)$ years were the largest. Among these patients seeking psychiatric consultation; 70 (61.9\%) were Hindu, 23 (20.4\%) Kirat, 10 (8.8\%) Buddhist, $3(2.7 \%)$ Muslims and $1(0.9 \%)$ Christian and $6(5.3 \%)$ were other religions. Most of the subjects 74 (65.5\%) were married, 35 (31.0\%) single, 1 (0.9\%) separated and $3(2.7 \%)$ divorcee. About $21 \%$ of the suicide attempt subjects were illiterate. (Table 1) 
Table 1

Socio-demographic characteristics:

\begin{tabular}{|c|c|c|}
\hline Characteristics & Categories & No. (\%) \\
\hline \multirow[t]{5}{*}{ Age in years } & $<20$ & $34(30.1)$ \\
\hline & $20-29$ & $39(34.5)$ \\
\hline & $30-39$ & 15 (13.3) \\
\hline & $40-49$ & $17(15.0)$ \\
\hline & $>50$ & $8(7.1)$ \\
\hline \multirow[t]{2}{*}{ Sex } & Female & $71(62.8)$ \\
\hline & Male & $42(37.2)$ \\
\hline \multirow[t]{4}{*}{ Marital Status } & Single & $35(31.0)$ \\
\hline & Married & $74(65.5)$ \\
\hline & Divorced & $3(2.7)$ \\
\hline & Separated & $1(0.9)$ \\
\hline \multirow[t]{3}{*}{ Residential setting } & Urban & $66(58.4)$ \\
\hline & Semi-urban & $23(20.4)$ \\
\hline & Rural & $24(21.2)$ \\
\hline \multirow[t]{7}{*}{ Education } & Illiterate & $24(21.2)$ \\
\hline & Literate- Grade 3 & $4(3.5)$ \\
\hline & Grade 4-7 & $19(16.8)$ \\
\hline & Grade 8 - SLC & $42(37.2)$ \\
\hline & Intermediate & $19(16.8)$ \\
\hline & Graduate & $4(3.5)$ \\
\hline & Higher & $1(0.9)$ \\
\hline \multirow[t]{4}{*}{ Occupation } & Homemaker & $40(35.4)$ \\
\hline & Farmer & $11(9.7)$ \\
\hline & Student & $33(29.2)$ \\
\hline & Others & $29(25.7)$ \\
\hline \multirow[t]{2}{*}{ Socioeconomic status } & Low & $59(52.2)$ \\
\hline & Middle & $46(40.70)$ \\
\hline
\end{tabular}




\begin{tabular}{|lll|}
\hline Characteristics & Categories & No. (\%) \\
\hline Religion & High & $8(7.07)$ \\
\hline Hindu & $70(61.9)$ \\
\hline Kirat & $23(20.3)$ \\
\hline Buddhist & $10(8.8)$ \\
\hline Muslim & $3(2.6)$ \\
\hline Christian & $1(0.9)$ \\
\hline Others & $6(5.3)$ \\
\hline Dalit & $17(15.1)$ \\
\hline Janajati & $50(44.2)$ \\
\hline Madhesi & $20(17.6)$ \\
\hline Muslim & $4(3.5)$ \\
\hline Brahmin/Chhetri & $17(15.1)$ \\
\hline Others & $5(4.4)$ \\
\hline
\end{tabular}

According to Personality trait Inventory; Emotional instability trait was present in the highest number of patients $70(61.9 \%)$, followed by Depressive tendency trait $46(40.7 \%)$. Introversion was present in 42 (37.2\%), Activity 37 (32.7\%), Social desirability 23 (20.4\%), Dominance 21 (18.6\%), Cyclothymia 20 (17.7\%), Paranoid tendency 14 (12.4) and Super ego was present in 10 (8.8\%). (Table 2) 
Table 2

Personality trait of Suicide attempt

Psychiatry out-patients cases

\begin{tabular}{|ll|}
\hline Personality trait & Frequency (\%) \\
\hline Activity & $37(32.7)$ \\
\hline Cyclothymia & $20(17.6)$ \\
\hline Superego & $10(8.8)$ \\
\hline Dominance & $21(18.5)$ \\
\hline Paranoid tendency & $14(12.3)$ \\
\hline Depressive tendency & $46(40.7)$ \\
\hline Emotional instability & $70(61.9)$ \\
\hline Introversion & $42(37.1)$ \\
\hline Social desirability & $23(20.3)$ \\
\hline
\end{tabular}

Most cases 63 (55.8\%) were referred from the Department of Internal Medicine, followed by Emergency Department 28 (24.8\%), self 18 (15.9\%) and Pediatrics Department 4 (3.5\%). (Fig. 1)

The common ICD-10 psychiatric diagnoses were: Substance use disorder, main being alcohol (42\%), Adjustment (34\%) and mood disorders (22\%). Emotional instability trait was the most common Personality Trait 70 (61.9\%), followed by Depressive tendency 46 (40.7\%). Personality disorder was present in 34\%; most common being Emotionally unstable personality disorder. (Table 3) 
Table 3

Psychiatric diagnosis among Suicide attempt Psychiatry out-patients cases

ICD Psychiatric diagnosis

No.

code

F10- Mental and behavioral disorders due to

F19 psychoactive substance use

Acute intoxication

4

Harmful use of alcohol

16

(14.1)

ADS

6

ADS in uncomplicated

withdrawal

ADS in complicated

withdrawal

Nicotine dependence

syndrome

Other substance

5

F20- Schizophrenia, schizotypal and delusional

Unspecified Psychosis

5

F29 disorder

F30- Mood disorder

F39

Severe depressive episode without PS

Moderate depressive episode

without SS

Mild depressive episode

1

without SS

Bipolar affective disorder

Recurrent depressive disorder

F40- Neurotic, stress related and somatoform disorder

Panic disorder

F48

Unspecified anxiety

Adjustment disorder 


\begin{tabular}{|c|c|c|c|}
\hline \multirow[t]{2}{*}{$\begin{array}{l}\text { ICD } \\
\text { code }\end{array}$} & \multicolumn{2}{|l|}{ Psychiatric diagnosis } & \multirow{2}{*}{$\begin{array}{l}\begin{array}{l}\text { No. } \\
\text { (\%) }\end{array} \\
4 \\
(3.5)\end{array}$} \\
\hline & & Acute stress reaction & \\
\hline \multirow[t]{4}{*}{ F60 } & \multirow[t]{4}{*}{ Specific personality disorder } & $\begin{array}{l}\text { Emotionally unstable } \\
\text { personality disorder }\end{array}$ & $\begin{array}{l}31 \\
(27.4)\end{array}$ \\
\hline & & Anxious personality disorder & $\begin{array}{l}4 \\
(3.5)\end{array}$ \\
\hline & & Schizoid personality disorder & $\begin{array}{l}1 \\
(0.9)\end{array}$ \\
\hline & & Paranoid personality disorder & $\begin{array}{l}2 \\
(1.8)\end{array}$ \\
\hline $\begin{array}{l}\text { Perso } \\
\text { Hospi }\end{array}$ & $\begin{array}{l}\text { ity Traits among Psychiatric } \\
\text { in Eastern Nepal }\end{array}$ & e Attempt Attending Tertiary Ca & \\
\hline
\end{tabular}

\section{Discussion}

In our study, Emotional instability trait was present in the highest number of patients 70 (61.9\%), followed by Depressive tendency 46 (40.7\%). Introversion was present in 42 (37.2), Activity 37 (32.7\%), Social desirability 23 (20.4\%), Dominance 21 (18.6\%), Cyclothymia 20 (17.7\%), Paranoid tendency $14(12.4)$ and Super-ego was present in 10 (8.8\%). Clinical and community researches suggest links between suicide attempts and psychological traits of aggression, anger and impulsivity. ${ }^{4}$

There is lack of literature, based on personality traits within the country and outside; our finding might open an avenue for further more intensive studies on individual personality traits.

Identifying personality disorder as risk factors for suicide attempts is an important consideration both for research and clinical care. We found that personality disorder was seen in $34 \%$ of the total cases where Emotionally unstable personality disorder and Anxious personality disorder were found in the highest number of patients. This finding corresponds to the study by Pandey et $\mathrm{al}^{13}$ in the same setting where $24 \%$ of the cases were found to have personality disorder, mainly Emotionally unstable impulsive subtype. Also a study by Risal A et al $^{14}$ found that Personality disorder was present in $26 \%$ of the patients admitted for intentional self-harm, mainly Emotional unstable personality disorder (impulsive type).

Our finding in BPKIHS was consistent with the study by Nabi $\mathrm{J}$ et $\mathrm{al}^{15}$ where most predominant type of personality disorder was Borderline personality $(28 \%)$. There was also a significant association $(P<0.05)$ between personality traits and past attempts interval, i.e. patients with Borderline personality traits were significantly associated with re-attempt suicide. Our finding also corresponds with Ansell Emily B et al ${ }^{16}$ where Borderline personality disorder was a significant predictor of any attempt in the presence of all personality disorders. Another study by Bhatt $\mathrm{M}$ et $\mathrm{al}^{17}$ found that impulsivity and borderline personality 
symptoms were significantly associated with attempted suicide. This suggests that symptoms of impulsivity in personality are strong predictors of suicide and may act in many ways by impairing the ability to cope with any situation and by drawing a person into conflicts with family members and others.

The mean age of our subjects was 28.27 years and the age range was $13-75$ years. This finding corresponds with the study by Shakya $\mathrm{DR}^{18}$ in the same setting with the average age of 29.68 years, age range of 15-81, and age groups (20-29) and < 20 years were the largest. This finding is in line of current literature indicating increasing suicide rates among young people. The age distribution was similar to the other study by Sapkota $\mathrm{N}$ et al ${ }^{19}$ conducted in the same setting where majority (67\%) of the suicide attempters were less than 35 years age and the commonest age groups attempting suicide in both the sexes were 15-24 years. Gender wise, among the suicide attempters visiting our OPD, 71 (62.8\%) were female and $42(37.2 \%)$ were male. Our finding was similar to the studies conducted in the same settings by Shakya $\mathrm{DR}^{18}$ with $57.39 \%$ and Sapkota $\mathrm{N}$ et al ${ }^{19}$ with $56 \%$ female subjects. This may be accounted to the fact that females are often exposed to the stress and strain of day to day life in our society.

In our study, 47 (42\%) was found to have Substance use disorder, mainly alcohol 28 (24.7\%) followed by Stress related and Neurotic disorder (34\%) mainly Adjustment (22\%) and mood disorder (22.1\%). The preponderance of substance and mainly alcohol problem among suicide attempt cases was consistent with a previous study of same institute. ${ }^{20}$ Among the mood disorders, most common was Severe Depressive Episode seen in (10.6\%) of the subjects. A study by Risal A et al ${ }^{14}$ found that maximum patients $(41.1 \%)$ were found to have Depression Spectrum Disorder (Depression, Dysthymia, Adjustment Disorder) as in our study.

Our finding also corresponds with the finding of the study done by Sapkota $\mathrm{N}$ et al ${ }^{19}$ in the same setting where mood disorder was found in $28 \%$ cases where Depression was reported in $22 \%$, followed by Adjustment disorder in $7 \%$ cases. Bansal $\mathrm{P}$ etal ${ }^{21}$ reported that majority of the suicide attempters were suffering from mood disorders (57\%) and Depression was found in $46 \%$ subjects, out of which $30 \%$ had Severe Depressive Episode. More research is needed to improve the prediction of suicide in mental disorders, along with more effective implementation of preventive measures.

\section{Conclusion}

Emotional instability trait was found in highest number of patients $70(61.9 \%)$, followed by Depressive tendency 46 (40.7\%) while personality trait was assessed using Personality Trait Inventory Questionnaire. Personality disorder was present in $34 \%$; most common being Emotionally unstable personality disorder. Among the suicide attempters; most common ICD-10 psychiatric diagnosis as was Substance use disorder, followed by Adjustment and Mood disorders. Majority of the psychiatric out patients with suicide attempters were female, married and literate, with the most common age group of 20-29 and < 20 years. Most of them were homemakers and from urban setting. 


\section{Abbreviations}

BPKIHS- B. P. Koirala Institute of Health Sciences

ICD-10- International Classification of Diseases and Infirmity

IRC- Institutional Research Committee

OPD- Out-patient department

SIH- Self-inflicted harm

\section{Declarations}

\section{Ethics approval and consent to participate-}

The study was done after obtaining the approval of Research Committee of BPKIHS (Ref. No. 403/074/075 and Code: IRC/1216/018). Cases were enrolled after informed written consent from the subject. Strict confidentiality of information was maintained and the results were utilized for management of the problem concerned and similar problems in general.

Consent for publication- Not applicable.

Availability of data and materials- All data generated during this study are included in this published article.

Competing interests- The authors declare that they have no competing interests.

\section{Funding- None. The authors, however, declare that they received logistic support from BPKIHS research committee.}

Authors' contributions- DRS and SSB were involved in all steps. NS, RGJ and MB were involved in research designing, assisting data collection and editing. BKD analyzed and interpreted the subjects' response regarding personality traits. All authors read and approved the final manuscript.

Acknowledgements- Dean Academics, BPKIHS and BPKIHS research committee

Authors' information- Supriya Sherchan (Bhattachan) (SSB), ${ }^{1}$ Dhana Ratna Shakya (DRS), ${ }^{2}$ Nidesh Sapkota (NS), ${ }^{3}$ Rinku Gautam Joshi (RGJ), ${ }^{4}$ Madhur Basnet (MB), ${ }_{4}^{4}$ Binod Kumar Deo (BKD) ${ }^{5}$

${ }^{1}$ Resident (when study conducted), ${ }^{2}$ Professor, ${ }^{3}$ Additional Professor, ${ }^{4}$ Associate Professor, ${ }^{5}$ Assistant Professor, Department of Psychiatry, B. P. Koirala Institute of Health Sciences, Dharan, Nepal

\section{References}


1. Sadock BJ, Sadock VA, Ruiz P. Kaplan and Sadock's, Synopsis of Psychiatry, 11th edition, Wolters Kluwer, 2014. Pp. $763-74$.

2. Sher L. Preventing suicide. QJM - Mon J Assoc Physicians. 2004;97(10):677-80.

3. Leo D, De, Padoani W, Scocco P, Lie D, Bille-brahe U, Arensman E, et al. Attempted and completed suicide in older subjects: results from the WHO / EURO Multicentre study of suicidal behaviour. Int J Geriatr Psychiatry. 2001;16:300-10.

4. Giegling I, Olgiati P, Hartmann AM, Calati R, Moller H, Rujescu D, et al. Personality and attempted suicide. Analysis of anger, aggression and impulsivity. J Psychiatr Res. 2009;43(16):1262-71.

5. Pompili M, Rihmer Z, Akiskal HS, Innamorati M, lliceto P, Akiskal KK, et al. Temperament and personality dimensions in suicidal and nonsuicidal psychiatric inpatients. Psychopathology. 2008;41(5):313-21.

6. Reich J. The Relationship of suicide attempts, borderline personality traits, and major depressive disorder in a veteran outpatient population. J Affect Disord. 1998;49(2):151-6.

7. Ansell EB, Wright AG, Markowitz JC, Sanislow CA, Hopwood CJ, Zanarini MC, et al. Personality Disorder Risk Factors for Suicide Attempts over 10 Years of Follow-up. Personality disorders. 2015;6(2):161-7.

8. Moeller FG, et al. Psychiatric aspects of impulsivity. Am J Psychiatry. 2001;158(11):1783-93.

9. Mann JJ, Waternaux C, Haas GL, et al. Toward a clinical model of suicidal behavior in psychiatric patients. Am J Psychiatry. 1999;156(2):181-9.

10. Bowen R, Baetz M, Leuschen C, Kalynchuk LE. Predictors of suicidal thoughts: mood instability versus neuroticism. Personal Individ Differ. 2011;51:1034-8.

11. Haw $\mathrm{C}$, Hawton K, Houston $\mathrm{K}$, Townsend $\mathrm{E}$. Psychiatric and personality disorders in deliberate selfharm patients. The British journal of psychiatry: J Mental Sci. 2001;178(1):48-54.

12. Bolton JM, Robinson J. Population-attributable fractions of Axis I and Axis II mental disorders for suicide attempts: findings from a representative sample of the adult, non-institutionalized US population. American Journal of Public Health. 2010 Dec; 100(12): 2473-2480.

13. Pandey AK, Shakya DR, Sapkota N. Clinical Correlates Associated with Suicide Attempters at a Tertiary Care Centre of Eastern Nepal. Int J Scie Study. 2015;3(1):4-8.

14. Risal A, Sharma PP. Psychiatric manifestations of patients admitted for intentional self-harm. Journal of Institute of Medicine. 2011;33:143-8.

15. Nabi J, Ghildiyal R. Personality traits of patients with attempted suicide: a hospital based study. Int J Res Med Sci. 2016;4(12):5399-404.

16. Ansell EB, Markowitz JC, Yen S, Pinto A, Girlo MC, et al. Personality Disorder Risk Factors for Suicide Attempts over 10 Years of Follow-up. Personal Disord. 2015;6(2):161-7.

17. Bhatt M, Perera S, Zielinski L, Eisen RB, Yeung S, El-Sheikh W, et al. Profile of suicide attempts and risk factors among psychiatric patients: A case-control study. PLoS ONE. 2018; 13(2): e0192998. https://doi.org/10.1371/ journal.pone.0192998. 
18. Shakya DR. Common Stressors among Suicide Attempters as Revealed in a Psychiatric Service of Eastern Nepal. J Trauma Stress Disorder Treat. 2014;3:3.

19. Sapkota N, Pandey AK, Shyangwa PM, Shakya DR, Thapa DK. Hundred psychiatric outpatients presented with attempted suicide. Health Renaissance. 2011;9(3):162-7.

20. Shakya DR. Alcohol Abuse/Use in Suicide Attempters: A Study in Psychiatric Out-Patient Clinic of a Teaching Hospital of Eastern Nepal. MOJ Addict Med Ther. 2018;5(1):00086.

DOI:10.15406/mojamt.2018.05.00086.

21. Bansal P, Gupta A, Kumar R. The Psychopathology and the Sociodemographic Determinants of Attempted Suicide Patients. Journal of Clinical Diagnostic Research. 2011;5(5):917-20.

22. Personality Traits among Psychiatric Out-patients with Suicide Attempt Attending Tertiary Care Hospital in Eastern Nepal.

\section{Figures}

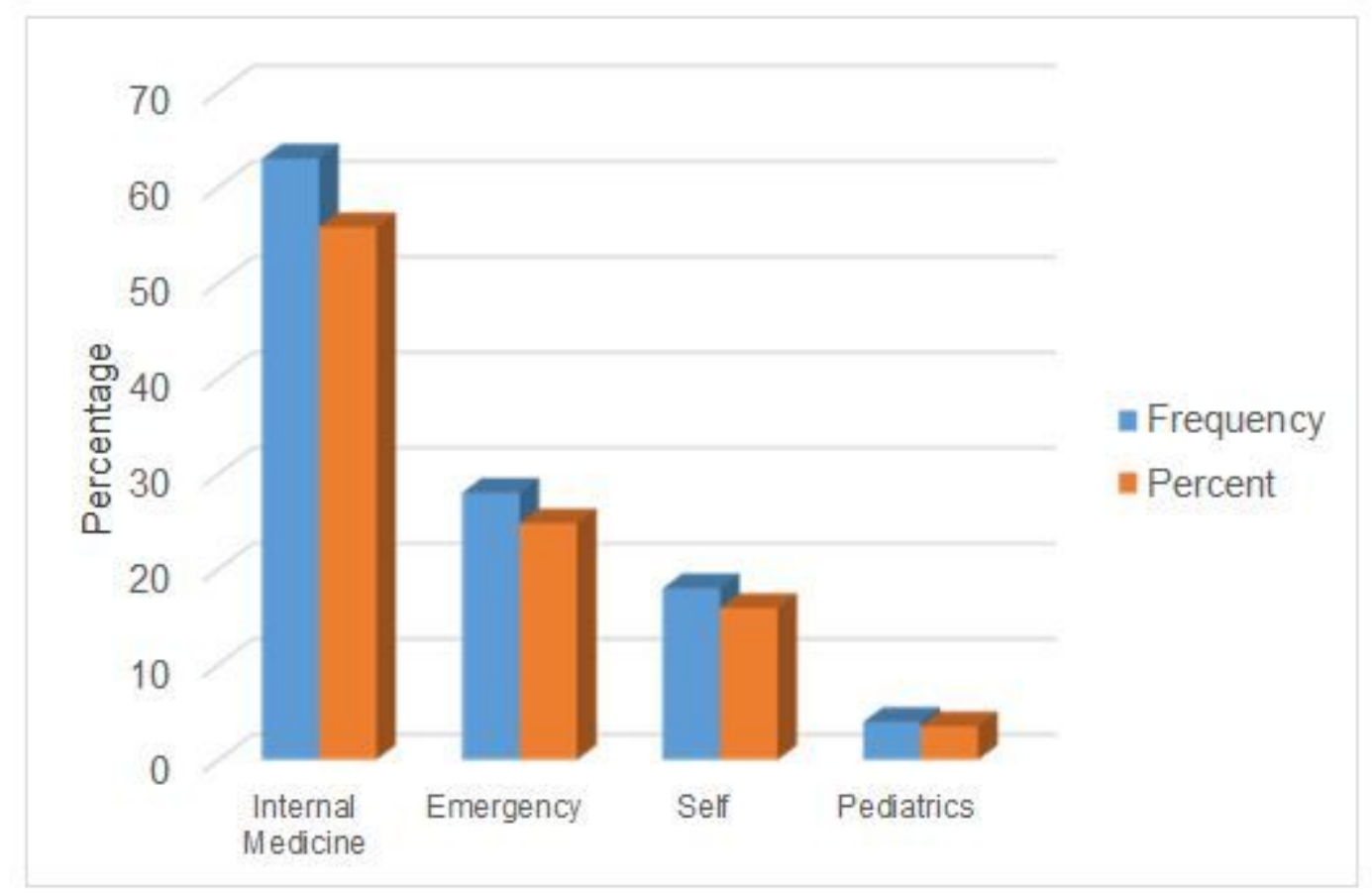

Figure 1

Source of Referral of suicide attempt cases 